\begin{tabular}{|c|c|}
\hline PORT SAID ENGINEERING RESEARCH JOURNAL \\
Faculty of Engineering - Port Said University \\
Volume 17 No.2 September 2013 pp: $12-17$
\end{tabular}

\title{
Technical Feasibility Study of Using Low Carbon Steel pipes in Natural Gas Pipeline Installations in the Egyptian Coastal Areas "Port Said and Alexandria"
}

\author{
Gowayed, W. A. ${ }^{1}$, Abdou, S. M. ${ }^{2}$, Abdel Rassol, S. ${ }^{3}$, Fouda, A. ${ }^{3}$ and Samy, S. M. ${ }^{2}$
}

\begin{abstract}
The aim of this study is to carry out a feasibility study for the use of four different types of steel pipelines to achieve the best type to be used for Natural Gas installations in the Egyptian coastal areas. Steel pipes that use in this purpose has exposed to different experimental tasks such as; morphology, hardness, machinability, bending, static pressure and corrosion behaviour. The results according to the technical feasibility study indicate that the Coru's pipe, El-Nasr's pipes and the Crane's pipes can be satisfactorily used in Egyptian coastal areas respectively. The El-Nasr's pipes gave good properties and best cost compared to the Coru's pipes. In same time more acceptable instead to the other investigated types in the Egyptian coastal areas.
\end{abstract}

KEYWORDS:Feasibility study, hardness, Bending, Machinability, Corrosion, Natural Gas, Low carbon steel, Pipeline, Cran's, El-Nasr's galvanic, El-Nasr's Coru's, Egypt pipes, El-Nasr steel pipes

\section{INTRODUCTION}

Corrosion of low carbon steel in natural gas pipeline is the greatest threat to the integrity of the installations and has often been compared to cancer in the human body. This is a very fitting comparison because each can potentially kill the body or structure by attacking the surface by any type of corrosion. Corrosion and deterioration of materials have serious economic impacts on our society and are therefore serious issues for managers [1]. Deterioration and corrosion of transportation infrastructure cost billions of dollars per year all over the world. These costs are attributable to; the reduction of facility service lives, costs of replacement, rehabilitation, and repair and increased construction costs to prevent or delay deterioration [24].

Feasibility studies aim to objectively and rationally cover the strengths and weaknesses of an existing business or proposed venture, opportunities and threats as presented by the environment, the resources required to carry through and ultimately the prospects for success. In simplest terms, the two criteria to judge feasibility are properties and value to be attained [5]. The five common factors which are studied in any modern technical feasibility study is mentioned as shorten by (TELOS) where $\mathrm{T}$ refers to Technical, $\mathrm{E}$ refers to Economic, L refers to Legal, O refers to Organizational and $\mathrm{S}$ refers to Scheduling. The (TELOS) is an acronym in project management used to define the five areas of feasibility that determine whether a project should run or not $[6,7]$.

The object of the feasibility study in the present work

\footnotetext{
${ }^{I}$ Project manager, Egypt gas co., Ismailia customer service, Egypt

${ }^{2}$ Department of Production Engineering and Mechanical Design, Faculty of Engineering, Port Said University, Egypt

${ }^{3}$ Department of Production Engineering and Mechanical Design, Faculty of Engineering, Mansoura University, Egypt
}

is to evaluate the technical and economic issues that would arise in natural gas pipelines installations for houses. This study looks at design to develop and improve materials and manufacture methods in order to increase the service life of the pipeline. This is achieved to reduce the capital and maintenance costs, improve the quality, performance and the properties of low carbon steel pipes. Hardness, Machinability and corrosion resistance were tested for the pipe materials. Different loading conditions were applied to the pipes, i.e. bending and static pressure. Four pipes made of four different types of steels were tested. Three pipes were obtained from the field and the forth was made by El-Nasr Steel Pipes and Fittings Co. The later pipe was a nongalvanized pipe, which conform to the European Standard. The design should be in accordance with the Natural Gas installation Pipelines European standard (EN 10255:2004+A 1), and the practical specifications and typical codes of the Natural Gas installations Engineers [8].

\section{EXPERIMENTAL DETALIES}

\subsection{Materials}

All of the pipes specimens used in the present study were made of low carbon steel with the chemical composition and the manufacturer of each steel pipe is shown in Table (1).

\subsection{Microstructure}

For the microstructure examination, samples were prepared by wet grinding, pre-polishing and "Minimet" polishing through $7 \mu \mathrm{m}$ and $1 \mu \mathrm{m}$ diamond paste using a Nylon polishing cloth. They were etched with a solution of $2-3 \%$ HNO3. The etching time was $30-90$ secs. The samples were heated before etching in hot water to improve the etching effect. 
Table 1: Chemical composition (wt \%) and. manufactures of the tested pipes

\begin{tabular}{|c|c|c|c|c|c|c|}
\hline Specimen & $\begin{array}{c}\text { Grade/ } \\
\text { Number }\end{array}$ & $\begin{array}{c}\mathrm{C} \\
\max \end{array}$ & $\begin{array}{c}\mathrm{Mn} \\
\max \end{array}$ & $\begin{array}{c}\mathrm{P} \\
\max \end{array}$ & $\begin{array}{c}\mathrm{S} \\
\max \end{array}$ & $\begin{array}{c}\text { Manufactures } \\
\text { notes }\end{array}$ \\
\hline $\begin{array}{c}\text { (A) } \\
\text { The } \\
\text { Crane's } \\
\text { pipes }\end{array}$ & $\begin{array}{c}\mathrm{S} 195 \mathrm{~T} \\
\text { No. } \\
10026\end{array}$ & 0.20 & 1.40 & 0.035 & 0.030 & $\begin{array}{c}\text { Butt-welded } \\
\text { pipe }\end{array}$ \\
\hline $\begin{array}{c}\text { (B) } \\
\text { The } \\
\text { Corus's } \\
\text { pipes }\end{array}$ & $\begin{array}{c}\mathrm{S} 195 \mathrm{~T} \\
\text { No. } \\
10026\end{array}$ & 0.13 & 0.7 & 0.025 & 0.020 & $\begin{array}{c}\text { Butt-welded } \\
\text { pipe }\end{array}$ \\
\hline $\begin{array}{c}\text { (C) } \\
\text { El-Nasr's } \\
\text { pipes }\end{array}$ & $\mathrm{X} 60$ & 0.052 & 1.12 & 0.013 & 0.002 & $\begin{array}{c}\text { Butt-welded } \\
\text { pipe } \\
\text { Resized by } \\
\text { hot rolling }\end{array}$ \\
\hline $\begin{array}{c}\text { (D) } \\
\text { El-Nasr's } \\
\text { galvanized } \\
\text { pipes }\end{array}$ & $\mathrm{X} 60$ & 0.052 & 1.12 & 0.013 & 0.002 & $\begin{array}{c}\text { Butt-welded } \\
\text { pipe } \\
\text { Resized by } \\
\text { hot rolling } \\
\text { Deep } \\
\text { galvanizing }\end{array}$ \\
\hline
\end{tabular}

\subsection{Hardness Test}

For hardness test, the Rockwell hardness testing machine was used. Loads of $10 \mathrm{kgf}$ and $100 \mathrm{kgf}$ were applied to the samples. The indenter was a ball of 1/16 inch. Samples for the hardness test were cut out of each pipes. Each data point of the hardness test was the average of three a adjacent readings.

\subsection{Machinability}

The machinability test was carried out on a center lathe machine on which the test rig was mounted. The tests were carried out using high speed steel tool. The machinability parameters involved in the present study are the chip compression ratio, cutting temperature and shape of chips.

\subsubsection{Chip compression ratio}

The chip compression ratio, $\lambda_{c}$, is determined experimentally as the ratio between the deformed chip thickness $\left(\boldsymbol{h}_{2}\right)$ and the undeformed chip thickness $\left(\boldsymbol{h}_{1}\right)$ as follow:

Where;

$$
\lambda_{c}=h_{2} / h_{1} \quad \text { and } \quad h_{1}=s \sin \phi
$$

$\boldsymbol{s}$ is the depth of the cut and $\phi$ is the shear plane angle. The chip thickness was measured using a $150 \mathrm{~mm}$ digital vernier caliper. Average chip thickness was obtained by averaging of 25-35 readings at different locations on the same chip.

\subsubsection{Cutting temperature}

The cutting temperature was measured by thermocouple sensor KDS-1002 (Thermocouple type K with temperature element: stainless steel with range: $200{ }^{\circ} \mathrm{C}$ to $1200{ }^{\circ} \mathrm{C}$ ). The thermocouple sensor was embedded into the rack face of the cutting tool via a very small groove that was cut in the tool face directly below the surface of tool and as close as possible to measure the chip-tool interface temperature.

\subsection{Bending Test}

This test was done according to the practical experience of Egypt gas company engineers due to the

safety and the pipelines lifetime precautions. The steel pipes specimen with dimension 1 meter length and $25 \mathrm{~mm}\left(1^{\prime \prime}\right)$ diameter have been prepared for each pipe brands. The bending tests were carried out in order to examine the bending effects on the welding strength and the wall thickness of each. The bending tests were performed using a Manual Hydraulic Pipe Bending Machines shown in Fig.1-a. The main affected areas of the pipe due to bending conditions are $(\mathrm{O} 1, \mathrm{O} 2$ and $\mathrm{O} 3)$ on the outer area and (I1, I2 and I3) on the inner area of bended pipe Fig.1-c. Figure 1-b show the ultrasonic apparatus which is used for measuring the change of steel wall thickness for the pipe.
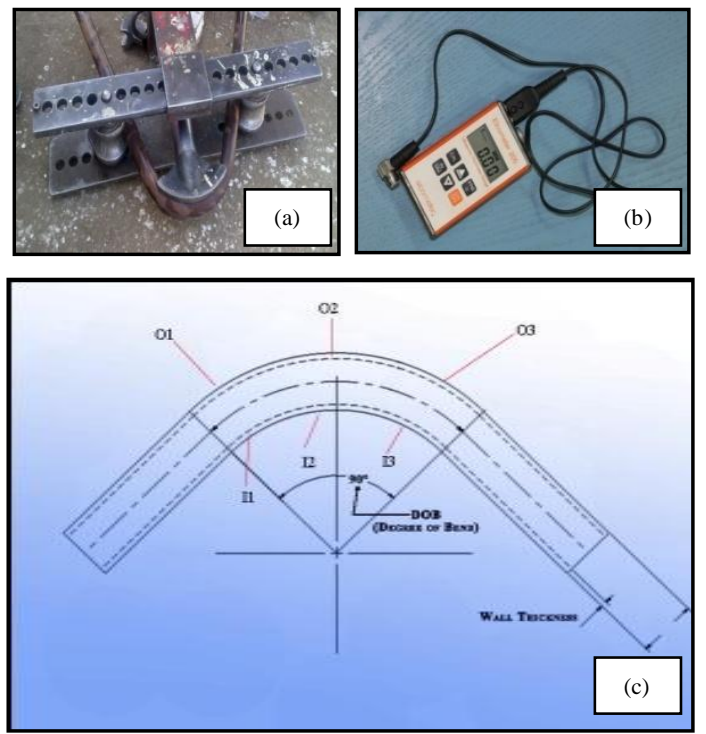

Fig.1: The bending apparatus (a) Manual hydraulic pipe bending machines, (b) Ul trasonic steel wall thickness gauge, (c) The main affected areas of the pipe due to bending.

\subsection{Static Pressure Test}

Five pipe of 1 meter length and $25 \mathrm{~mm}$ ( 1 ") diameter of steel pipes with threaded ends have been prepared from each pipe brands. Each specimen were subjected to hydrostatic pressure of Nitrogen under pressures 30, 40, 50 and 90 bars for 5 minute and barometer device used to monitor any leakage. The pressure test schematic is shown in Fig. 2.

$$
\begin{aligned}
& \text { Parts: } \\
& \text { 1- Nitrogen cylinder } \\
& \text { 2- Bale valve } \\
& \text { 3- Pressure gauge } \\
& \text { 4- Specimen }
\end{aligned}
$$

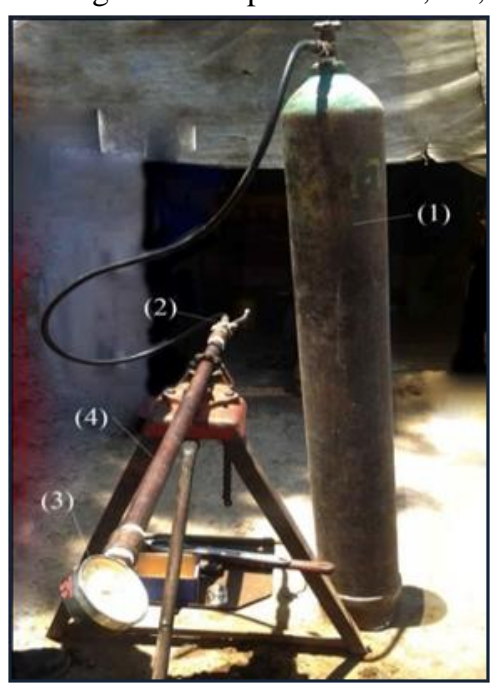

Fig.2: Equipment used for the hydrostatic pressure test. 


\subsection{Corrosion Test}

Corrosion test was done according to ASTM G102: standard practice for calculation of corrosion rates and related information from electrochemical measurements (potentiometer method) which, gives fast and accurate results of the corrosion rate. Potentiometer is a device which will apply a potential (voltage) across a pair of electrodes and simultaneously measures the current which flows through a solution of an analyte. The electrodes are called the working electrode (test specimen) and the auxiliary (counter) electrode as shown in Fig.3-a.The current which flows through the working electrode can be measured by Electrochemical PC card (Fig.3-b) and the results plotted in a graph called the linear polarization curve, which give a complete image about the corrosion behavior of the tested steel pipes.

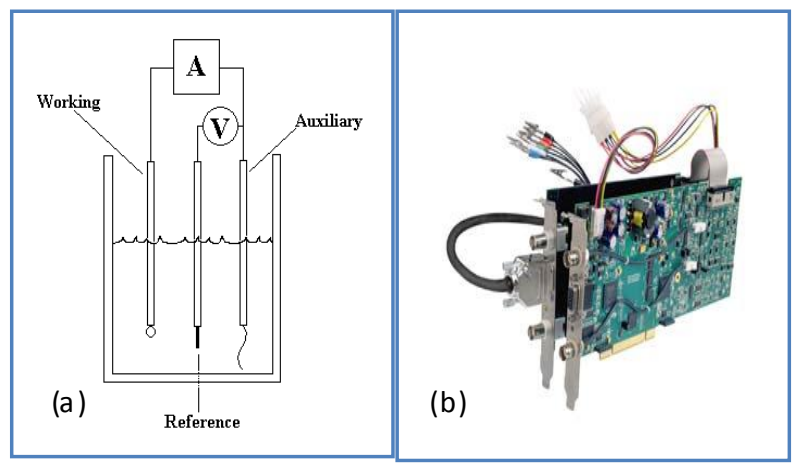

Fig.3: Electrochemical corrosion test

(a) The test cell diagram. (b) Electrochemical PC card.

\section{RESULTS AND DISCUSSION}

The purpose of the present work is to perform a feasibility study of using low carbon steel pipes for industrial applications of natural gas installations at the Egyptian coastal areas.

\subsection{Morphology}

The mic rostucture examination showed the appearance of the formation phases for all types of the investigated low carbon steels. The low carbon steel has two major constituents, i.e. ferrite and pearlite, see Fig.4. It contains about $0.05-0.2 \%$ of Carbon by weight. The light colored region of the microstructure is the ferrite. The grain boundaries between the ferrite grains can be seen quite clearly. The dark regions are the pearlite phase. It is made up from a fine mixture of ferrite and iron carbide, which can be seen as a "wormy" texture. It can be also see small spots within the ferrite grains. These are inclusions or impurities such as oxides and sulphides.

The properties of low carbon steel depend upon its microstructure. The strength, ductility and the toughness of the low carbon steel depend on the size of the grains. Decreasing the grain size and the amount of pearlite improve this properties. The machinability parameter such as chip formation achieved this matter.
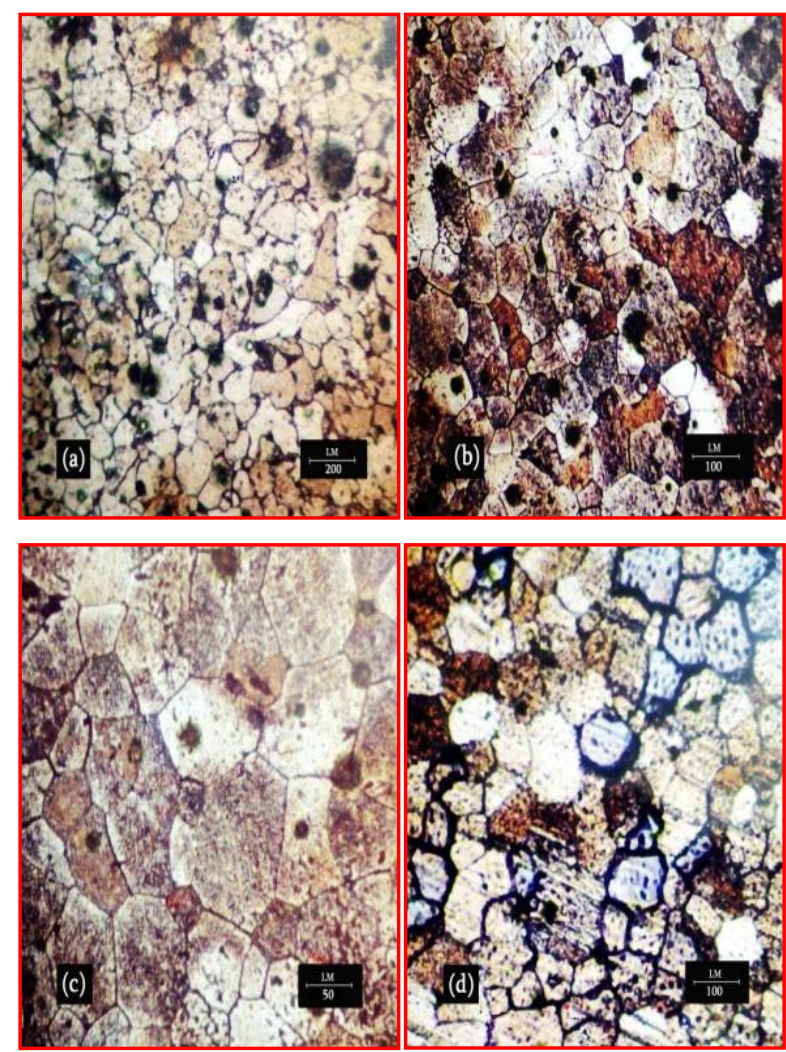

Fig.4: light micrograph (LM) for the microstructure of investigated steel pi pe (a) pipe specimen (A), (b) pi pe specimen $(B),(c)$ pi pe s pecimen $(C)$ and (d) pi pe specimen (D)

\subsection{Hardness}

The hardness of a pipe material affects its machinability, such as cutting, threading, bending and resistance to deformation under applied pressures. Therefore, it is necessary to measure the hardness of the material of the pipes under investigations. Fig.5 compares the percent of failed pipes to the hardness of the pipe materials for the pipes under the current investigations. It can be clear that the best pipe type is the Crane's pipe specimen (A), and both El-Nasre's pipe specimen (C) and Coru's pipe specimen (B) has more waste losses by about (7-9)\% of the total sample. While specimen (D) is the worst type one by about $15 \%$ of the total sample.

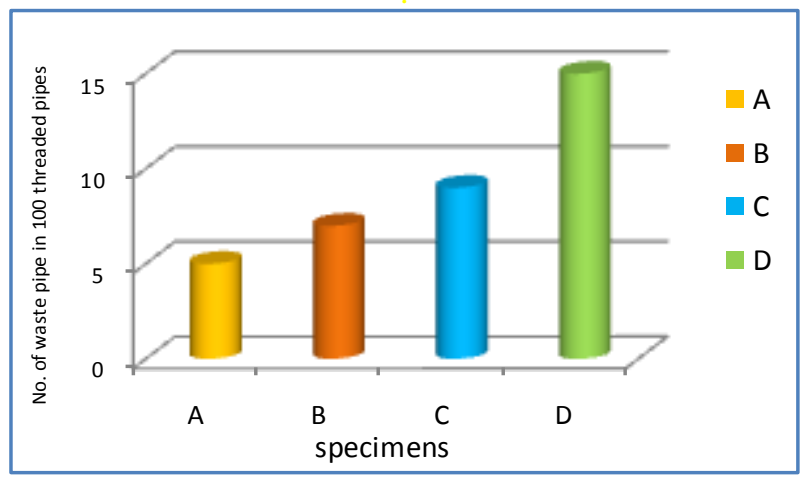

Fig.4: the waste of steel pipes for different types of investigated steel pipes during threading due to The macrohardness. 


\subsection{Machinability}

The goal of studying the machinability is to provide knowledge of machining steel pipe with further improvements in the machining cost. The relationship between the cutting speed versus the chip compresion ratio $\lambda_{c}$ for low carbon steel specimens (A, B, C and D) at different feed rate is shown in Fig.6.

Three distinctive regions are noticed regarding the functional interrelation. The first; at low cutting speeds, a larger deformed chip thickness is obtained. However, within this domain, increasing cutting speed change the chip flow and hence the formation of the built-up edge (BUE) which reduces the area of contact between the chip underside and the tool face and that results in a lower friction and hence lower $\lambda \boldsymbol{c}$.

The second domain; at low to moderate cutting speed, where the formation of BUE is less possible, $\lambda_{c}$ increases reaching its highest value (thicker deformed chip thickness).

Further cutting speed increase; the third region, usually improves process stability and more uniform chip thickness. This may be attributed to the reduction of flow stress that results in a smaller friction coefficient on the tool face and hence lower $\lambda c$. For all the feed rate ranges, similar patterns are observed and it can be seen that $\lambda c$ is decreased with the increase of the feed rate.

With the increasing of the cutting speed, the amount of heat generated in cutting is increased as shown in Figs.7. On the other hand, the time allowed for heat transfer at the chip-tool interface is decreased which leads to a degressive increase of the cutting temperature with the cutting speed. Also, It can be remarked that the effect of the feed rate on the cutting temperature is considerably less than that of the cutting speed. With the increase of the feed, the cutting temperature degressively increased, due to the simultaneous effect of the feed rate on the cutting force and on the area of contact at the chip-tool interface and hence the area of heat dissipation.

The increase of the feed rate causes the increase of the cutting temperature until a certain value of the feed rate is attained after which the cutting temperature becomes almost independent on the feed rate due to the direct increase of the heat dissipation area at the chip-tool interface, and consequently the increase of the amount of heat dissipation.

\subsection{Corrosion}

The corrosion potential for the four specimens at five temperatures are tabulated in Table $\mathbf{2}$ to compare between the corrosion behavior of each specimen and the effect of increasing temperature. Figure 8 shows the corrosion temperature versus the corrosion current for four pipe specimens. It can be seen the corrosion current increases as the corrosion temperature increases. Furthermore, the corrosion current for specimen $\mathrm{A}$ is the maximu $m$ and $D, C$ and $B$ is respectively lower.

The corrosion rates for the four pipe specimens at five temperatures are tabulated in Table $\mathbf{3}$ to compare between the corrosion behavior of each specimen and the effect of temperature increasing. Figure 8(b) shows the temperature versus the corrosion rate for four pipe specimens. It can be seen that the corrosion rate increases as the temperature increases Moreover, it can
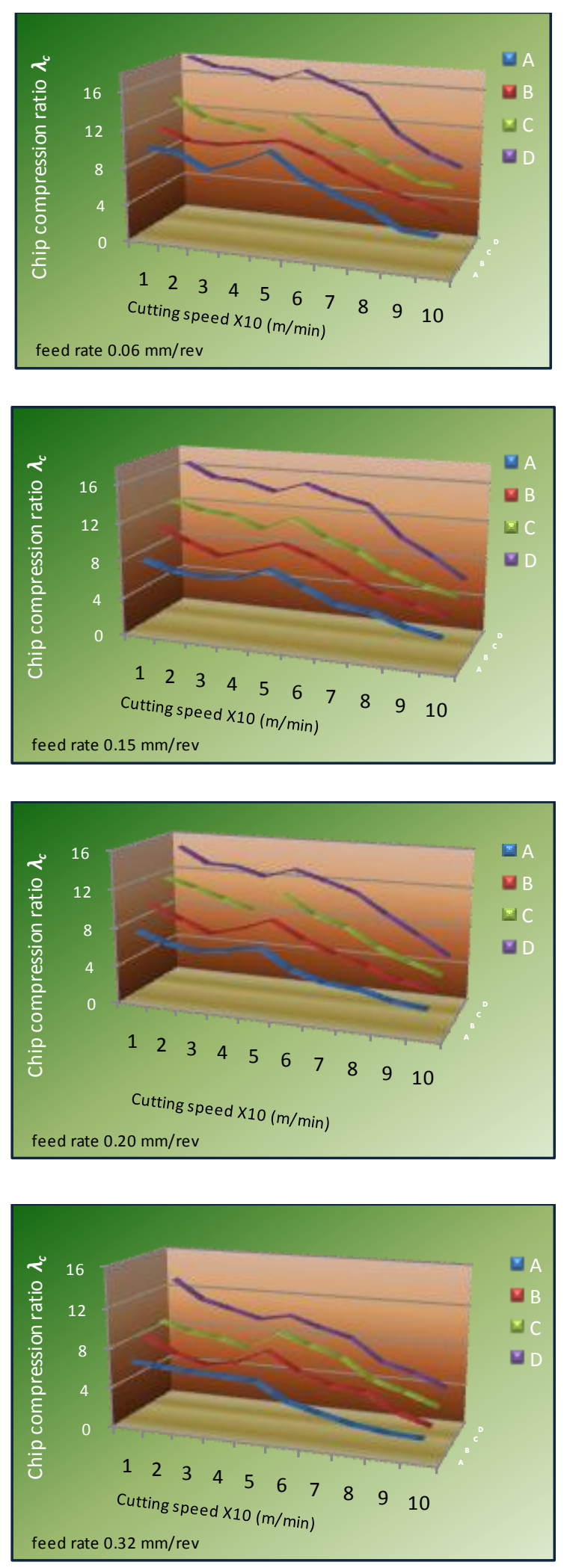

Fig.6: The relaionship between the chipcompresion ratio at different cutting speed for all specimens $(A$, $B, C$ and $D$ ) at feed $r$ ate $0.06,0.15,0.20$ and 0.32 $\mathrm{mm} / \mathrm{rev}$ and depth of cut $0.5 \mathrm{~mm}$ for low carbon steel. 

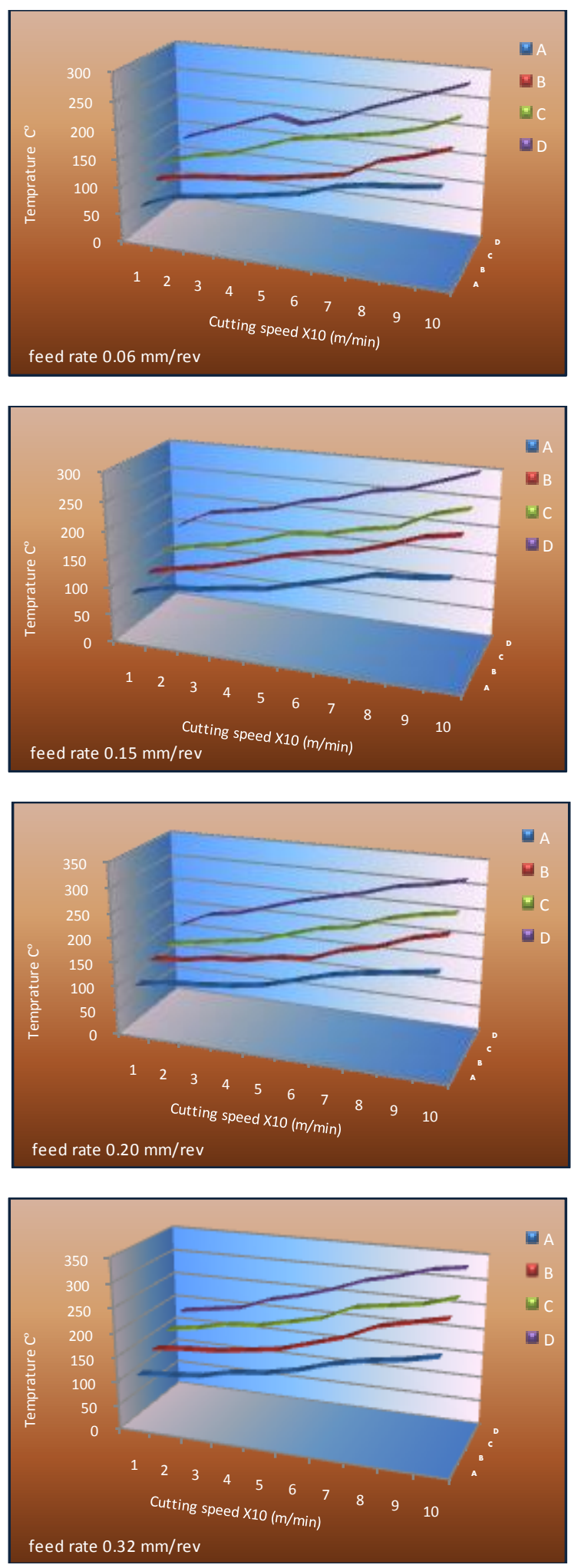

Fig.7:The relationship between the cutting speed versus the temprature for all low carbon steel specimens $(A, B, C$ and $D)$ at feed rate $0.06,0.15,0.20$ and $0.32 \mathrm{~mm} / \mathrm{rev}$ and depth of cut $0.5 \mathrm{~mm}$.

be seen that the specimen $\mathrm{B}$ has the lowest corrosion rate and $(\mathrm{C}, \mathrm{D}$ and $\mathrm{A})$ are respectively higher and this arranging doesn't change with temperature increases.

\subsection{Direct Cost}

The cost of the low carbon steel pipes is a direct cost,
Table 2: The corrosion current $\mathrm{A} / \mathrm{cm}^{2}$ for each specimen at five different temperatures.

\begin{tabular}{|c|c|c|c|c|c|}
\hline specimen & $27{ }^{\circ} \mathrm{C}$ & $35{ }^{\circ} \mathrm{C}$ & $40{ }^{\circ} \mathrm{C}$ & $45{ }^{\circ} \mathrm{C}$ & $50{ }^{\circ} \mathrm{C}$ \\
\hline \multirow{2}{*}{$\mathrm{A}$} & $\begin{array}{c}4.84 \mathrm{E}- \\
05\end{array}$ & $\begin{array}{c}6.47 \mathrm{E}- \\
05\end{array}$ & $\begin{array}{c}9.36 \mathrm{E}- \\
05\end{array}$ & $\begin{array}{c}9.55 \mathrm{E}- \\
05\end{array}$ & $\begin{array}{c}1.58 \mathrm{E}- \\
04\end{array}$ \\
\hline \multirow{2}{*}{$\mathrm{B}$} & $\begin{array}{c}1.80 \mathrm{E}- \\
06\end{array}$ & $\begin{array}{c}9.25 \mathrm{E}- \\
06\end{array}$ & $\begin{array}{c}1.35 \mathrm{E}- \\
05\end{array}$ & $\begin{array}{c}1.86 \mathrm{E}- \\
05\end{array}$ & $\begin{array}{c}2.44 \mathrm{E}- \\
05\end{array}$ \\
\hline $\mathrm{C}$ & $1.36 \mathrm{E}-$ & $2.38 \mathrm{E}-$ & $3.01 \mathrm{E}-$ & $3.36 \mathrm{E}-$ & $4.02 \mathrm{E}-$ \\
05 & 05 & 05 & 05 & 05 \\
\hline $\mathrm{D}$ & $3.44 \mathrm{E}-$ & $4.75 \mathrm{E}-$ & $5.35 \mathrm{E}-$ & $6.55 \mathrm{E}-$ & $7.23 \mathrm{E}-$ \\
& 05 & 05 & 05 & 05 & 05 \\
\hline
\end{tabular}
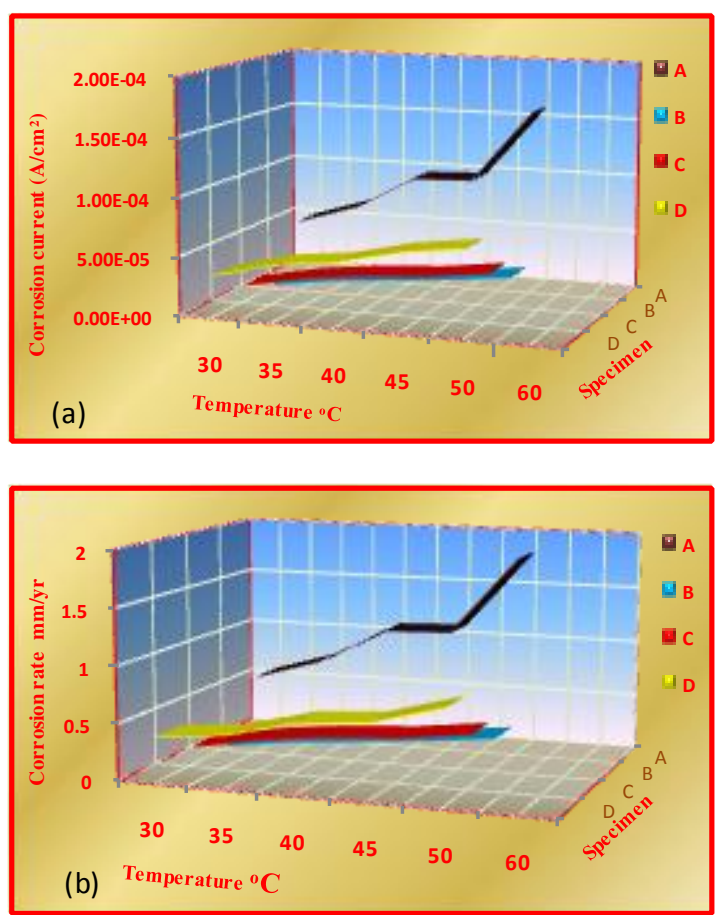

Fig. 8: The relationship between the temperature versus corrosion current $\left(A / \mathrm{cm}^{2}\right)$ for different low carbon steel pipe (A, B, C and D).

Table 3: The corrosion rates $\mathrm{mm} / \mathrm{yr}$ for each pi pe specimen at five different temperatures.

\begin{tabular}{|c|c|c|c|c|c|}
\hline specimen & $27{ }^{\circ} \mathrm{C}$ & $35{ }^{\circ} \mathrm{C}$ & $40{ }^{\circ} \mathrm{C}$ & $45{ }^{\circ} \mathrm{C}$ & $50{ }^{\circ} \mathrm{C}$ \\
\hline $\mathrm{A}$ & 0.548 & 0.733 & 1.06 & 1.081 & 1.793 \\
\hline $\mathrm{B}$ & 0.02 & 0.105 & 0.153 & 0.211 & 0.277 \\
\hline $\mathrm{C}$ & 0.154 & 0.269 & 0.34 & 0.38 & 0.456 \\
\hline $\mathrm{D}$ & 0.389 & 0.45 & 0.606 & 0.65 & 0.819 \\
\hline
\end{tabular}

which vary from type to type and size to size due to manufacturing methods, row material cost and the quantity of production. Table 4 shows the price of one meter of the four pipe brands and two pipe sizes used in natural gas installations according to the market prices and the evaluation of the new low carbon steel manufacture in El-Nasr Steel Pipes \& Fittings (special pipes) and the experimental results including the hardness, machinability, applied pressure, bending and corrosion behavior. 
Table 4: The investigated parameter for choosing the best low carbon steel pi pes for natural gas installations accor ding to the experimental results.

\begin{tabular}{|c|c|c|c|c|c|c|c|c|c|c|c|c|c|c|c|c|}
\hline \multirow{2}{*}{$\begin{array}{l}\text { Parameter } \\
\text { Specimens }\end{array}$} & \multirow{2}{*}{$\begin{array}{c}\text { Hardness } \\
\text { HRB }\end{array}$} & \multicolumn{2}{|c|}{ Machinability } & \multicolumn{4}{|c|}{ Pressure (bar) } & \multicolumn{2}{|c|}{ Bending } & \multicolumn{5}{|c|}{ Corrosion rate at different temperatures ${ }^{\circ} \mathrm{C}$} & \multicolumn{2}{|c|}{$\begin{array}{l}\text { Current Price } \\
\mathrm{LE} / \text { meter } \\
\text { for diameters }\end{array}$} \\
\hline & & $*^{1} \mathrm{CCR}$ & $*^{2} \mathrm{~T}$ & 30 & 40 & 50 & 90 & $*^{3} \mathrm{O}$ & $*^{3} \mathrm{I}$ & 27 & 35 & 40 & 45 & 50 & $\begin{array}{l}20 \mathrm{~mm} \\
(3 / 4 ")\end{array}$ & $\begin{array}{c}20 \mathrm{~mm} \\
(1 ")\end{array}$ \\
\hline A & 53.408 & 8.3 & 120 & $*^{4} \mathrm{P}$ & $\mathrm{P}$ & $\mathrm{P}$ & $\mathrm{P}$ & $\mathrm{P}$ & $\mathrm{P}$ & 0.548 & 0.733 & 1.06 & 1.081 & 1.793 & 18.62 & 26 \\
\hline B & 57.883 & 9.9 & 130 & $\mathrm{P}$ & $\mathrm{P}$ & $\mathrm{P}$ & $\mathrm{P}$ & $\mathrm{P}$ & $\mathrm{P}$ & 0.02 & 0.105 & 0.153 & 0.211 & 0.277 & 19 & 27.5 \\
\hline $\mathrm{C}$ & 65.608 & 11.2 & 180 & $\mathrm{P}$ & $\mathrm{P}$ & $\mathrm{P}$ & P & $\mathrm{P}$ & $\mathrm{P}$ & 0.154 & 0.269 & 0.34 & 0.38 & 0.456 & 15.5 & 24 \\
\hline D & 74.841 & 16 & 195 & $\mathrm{P}$ & $\mathrm{P}$ & $*{ }^{5} \mathrm{~F}$ & F & F & $\mathrm{P}$ & 0.389 & 0.45 & 0.606 & 0.65 & 0.819 & 14 & 18 \\
\hline
\end{tabular}

${ }^{* 1} \mathrm{CCR}$ is chip compression ratio ${ }^{* 2} \mathrm{~T}$ is cutting temperature ${ }^{* 3} \mathrm{O} \& \mathrm{I}$ is the outer and inner bending area $*^{4} \mathrm{P}$ is pass. ${ }^{* 5} \mathrm{~F}$ is fail.

\section{CONCLUSIONS}

The conclusions from the results and discussions to choose the suitable local steel instead of the imported steel pipe for the industrial application of low carbon steel pipes for natural gas installations on the coastal areas under the experimental variables such as the morphology, hardness, machinability, static bending, applied pressure and corrosion rate leads to the obviously guides to the following:

- The specimen "D" (El-Nasr Steel Pipes \& Fittings the galvanized pipes) cannot be used in natural Gas installations fields.

- The specimen "C" (El-Nasr Steel Pipes \& Fittings the special pipes) can be a good alternative solution for the imported pipes specimens "A" (CRANE) and "B" (CORUS).

\section{REFERENCES}

[1] "Egypt Gas company information center, annual report", PP. 1-33 , Cairo, 2011

[2] Smarter Materials Selection for Corrosion Control, Parker Hannifin, United Kingdom, 1-12, (2008)

[3] "Pipeline Accident Report Natural Gas Pipeline Rupture and Fire Near Carlsbad", National Transportation Safety Board, New Mexico, PP.166, (2000)
[4] Gerhardus H. Koch, Michiel P.H. Brongers, and Neil G. Thompson: "Corrosion Costs and Preventive Strategies in the United States", NACE international, USA, 1-12, (2008)

[5] Business Feasibility Study Outline, UPS and business planning, Alan Thompson institution, 185-198, (2005).

[6] John W. Brockhouse, Jr., and James J.: "A Cooperative Feasibility Study Guide", South Carolina, Service Report 58 PP.1-31, (2010).

[7] W. Heath Hoagland and Lionel Williamson:'Feasibility Studies", University of Kentucky, Lexington, PP.1-3, (2000).

[8] European standard (EN 10255-2004+A1), Technical committee ECISS/TC29, PP.1-26, (2007)

[9] Mason Dane Morehead: "Machinability and Microstructure Stability During the Machining of Pure Copper and Titanium Processed by Equal Channel Angular Pressing”, Clemson University journal, PP.1-167, (2007).

\section{ACKNOWLEDGEMENTS}

The authors are grateful to the Mansoura University, Faculty of Eng ineering for provid ing necessary facilities for this work. 